\title{
The Vital Role of Ensuring On-Going Relevance During A Period of Unprecedented Change, Due To COVID-19; An Ability to Identify and Understand Timeless Narratives Takes on Greater Utility for Communications Efficiency
}

\author{
Chris D Beaumont ${ }^{1 *}$, Darrell Berry ${ }^{2}$, Kallin Ricketts ${ }^{3}$ and John Ricketts ${ }^{2}$ \\ ${ }^{1}$ Institute for Future Initiatives, LifeStyle by Design, The University of Tokyo, Japan \\ ${ }^{2}$ Significance Systems, Sydney NSW 2069, Australia \\ ${ }^{3}$ Seisen International, Tokyo, Japan
}

Submission: April 19, 2021; Published: May 25, 2021

"Corresponding author: Chris D Beaumont, Institute for Future Initiatives, Lifestyle by Design, The University of Tokyo, 7-3-1 Hongo, Bunkyo-Ku, Tokyo 113-0033, Japan

\section{Abstract}

Several key lifestyle narratives are tracked before and during the global COVID-19 pandemic, comparing the situation in Japan and the UK. Most social media content is transient and has no engagement. Timeless and transformational narratives have utility as they have the potential to effect change, in attitudes and behaviour to create sustainable value.

This paper explores some timeless lifestyle narratives during a period of extraordinary socio-economic and political uncertainty. The nature of timeless narratives, while enduringly relevant, are not static. It is important to be able to understand how the expression changes to remain relevant. Leveraging Big Data and AI to identify specific content (topics, triggers, media channels...) that drive past and future outcomes. The ability, promptly, to go beyond volumetric measure of a topic and understand what is significant, has never been more important to help improve decision-making with a better strategic understanding and ability to connect with your audience.

Keywords: Engagement; Utility; Timeless; Narrative; Relevance; Behaviour; Lifestyle; Better decisions

\section{Introduction}

COVID-19 will go down as a rare event in human history, first an unprecedented human tragedy. It has completely disrupted the status quo, changing everyone's daily lives, heightening uncertainty, so that no one can take even the little things in life for granted. For many, the future was fast-forwarded by the pandemic. Certainly, the internet has played an increasingly central role in people's lives. Beyond the ability to connect remotely and telework, it is evident that it played a central role in disseminating information that led to people to act, often quicker than governments. "COVID-19 may go down in history as the internet's first truly great informational triumph" suggests Gans [1], who rightly views the pandemic as highlighting an information problem [2].
The internet is built of connected minds exhibiting behaviors in response to a stimulus. Social media fuels the imagination, impacts attitudes and behaviour [3], and facilitates the marketing of products and services [4] and increasingly with social distancing driving e-commerce, it is changing the customer journey [5] and marketing response. Indeed, mass media continues to lose its influence with analytics and Big Data increasingly driving personalization, with video playing an ever-increasing role on smart devices. Dehghani et al., [6] empirical study discovered four dimensions that have an influence on YouTube advertising; customization, informativeness, entertainment, and irritation that influenced brand awareness, and purchase intention. More significantly from 
a corporate perspective is the fact that the COVID-19 pandemic has created an "epidemic of misinformation...... in an environment of information bankruptcy" [7]. This leads one to hypothesise that the questions of governance and social responsibility will shift from government and media providing opportunities, especially for transnational corporations. If the pandemic brought technology transformation to the fore, and for many fast-forwarded the future, it has for some led to a reappraisal of traditional creative industries [8]. Together, these transformational triggers will in many countries set in motion a re-evaluation of the social contract.

With the rise in the importance of the internet, digital insight platforms, such as social listening, have provided quick access to volumetric measures of comments. Mentions of a topic are categorized and counted, then averaged and subtracted for sentiment. However, frequency is not uniformly significant, especially in the digital context where personalization is the key characteristic of engagement. In this approach, the signal of 'what is important' is not isolated from the noise of 'what is not'. While such platforms can provide quick measures of the penetration of themes but lack predictive reliability in terms of identifying likely future outcomes. Two of the authors, who Forbes [9] recognized for originally coining the term "social media" wanted something better and developed earth.ai; a platform for strategic understanding and forward-looking decision-making.

earth.ai, a predictive insight engine, captures and synthesizes this structure in an unbiased way. The process takes all open data online as contending for consideration. It analyses vast amounts of unstructured raw data from across the internet to model human behavioural interactions with content, to present an authentic, nuanced view of the emotions that drive mass behaviour. In this way, the internet is leveraged as a 'massive behavioral test' to gauge the importance of specific content (topics, triggers, media channels, ...) (Figure 1).

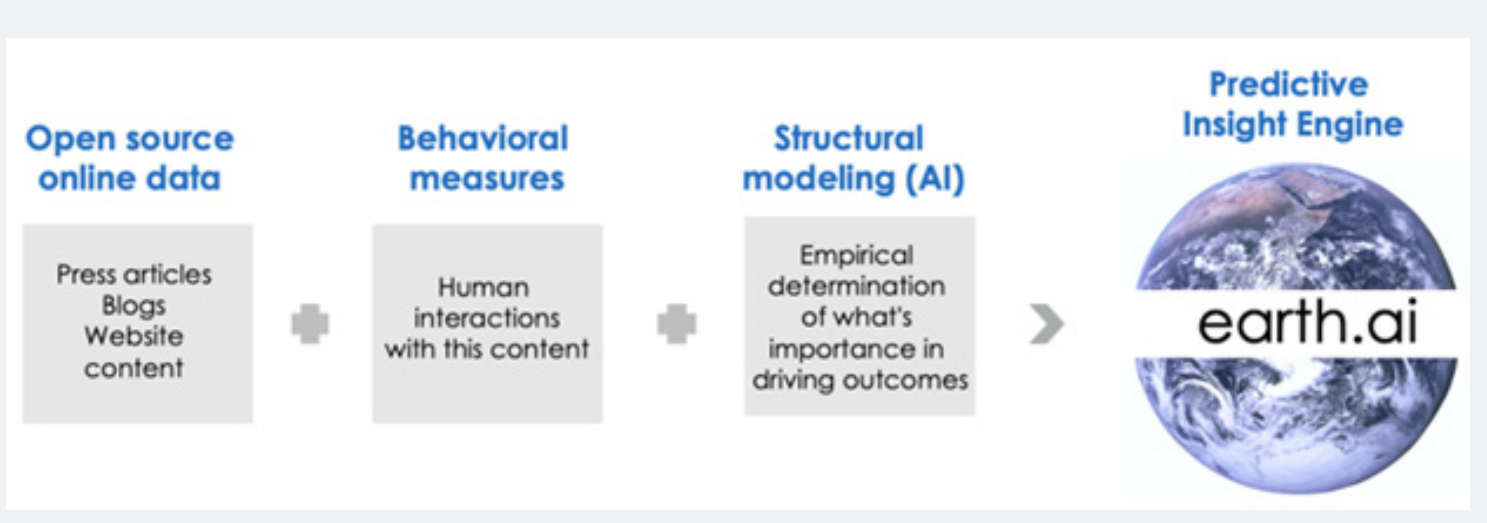

Figure 1: Al Used to identify what is significant in driving behaviour @Significance Systems (used with permission).

The methodology that Significance Systems adopt is a computational-reductionist approach long term engagement for narratives that include both traditional and social media. As a first step, it harnesses multiple layers of processing, within the petabytes of raw topical data available, to identify and extract human-meaningful, social-signaling structure. This markedly reduces the volume of data to which one can then apply computationally intensive, linguistic, processes such as detailed grammatical analysis and natural language processing, to focus on the strong story. Understanding of the emotional depth of the narrative allows for better understanding and connection with people. To this end, the methodology can sense and quantify over 400 named emotional states in response to any story.

For each narrative, discrete structural characteristics are found as well as identifying the levers that drive them. It is known that distinct types of narratives behave in discrete ways, and very in their value and utility. Throughout many studies and obser- vations, repeating patterns and structures have been identified. Significance Systems have developed techniques to automatically categorize and describe narratives based on those structures. Crucially, these mathematical patterns correlate well with real-world outcomes related to those narratives, and highlight the significant media, actors and topics through which engagement with those narratives drives attitudinal and behavioural change.

Thus, it is possible to identify the nature of any given narrative, and in the appropriate manner of engagement with it. This is achieved by exploring the communications power that underlines different evolutions of stories. The affect around every narrative can be analyzed. It is important because it is the foundation of emotion. Most narratives are simply neutral and do not provoke any emotional response. However, it is possible to determine the affect orientation to measure the degree to which the narrative does stimulate an emotional response: whether active or passive and positive or negative. 
As such affect is a strong predictor of behavior. In this way, it helps understand what is significant to people in real-time, and not what commentators, companies, or politicians think is important. COVID-19 has shown that you cannot mistake confidence with competence. Rather than offering a 'magic- bullet' for all communication, for many people, 'social' constitutes simply a regular update on an already formed position. A viewpoint primed by the perceived authority of other sources.

Moreover, the rise of the mobile internet has changed markedly the nature of memes from "edgy and esoteric" [10] to natural and nurturing; a dynamic that was too often not embraced by public and private commentators during the pandemic. Thus, at times, poor communications made the situation worse by miscommunicating and creating confusion (blue in Figure 2) and heightening anxiety and distress. The issue is not one of propaganda, safety versus economy, but the need for clarity, timely and transparent communications to engage and establish public trust when the unexpected and unthinkable was happening. The first national lockdown in the UK represented at the time a major shift in government policy, following modeling by a leading epidemiologist [11], and in the year that followed changing circumstances necessitated two further national lockdowns, necessitated after scientists recommendations for short, 'circuit breaker' lockdowns went unheeded. Naturally during a crisis the nature of risk management itself can evolve, but it should change transparently.

Figure 2: COVID-19 Affect March 2020-March 2021- one year since first national lockdown in the UK.

During the covid crisis many studies tracked consumer behavior and consumer sentiment, but we're rather more concerned with comparing economic optimism between countries and changes in behavior [12], with a focus on when and if their routines would return to normal, than the emotional impact of the pandemic. Others have taken the opportunity to undertake a literature review to deepen the theoretical knowledge of sentiment during epidemic and disease outbreaks [13]. Both, while adding to knowledge, do not help in executing a timely communication plan to confirm policy clearly to different constituencies during a period of uncertainty and misinformation. Issue analyses utilizing established qualitative techniques, online [14] can at best be viewed as Pre Search, to help refine hypotheses, given the low respondent sample size and potential recruitment bias.

It is common in communications planning that the objective is to 'create engagement'. However, it is much more effective to recognize that the world is already rich with engagement 'in the wild'. In this vein, we take the view that social media constitutes simply a regular update on an already formed worldview, itself informed by the perceived authority of other sources. During the COVID-19 crisis inadequate understanding of the transient nature of the communications power of media channels and the potential value of a relatively small number of 'thought leaders' to influence the masses. When broadcast, mass communications prevailed a single truth would dominate. Today's fragmentation, with almost infinite channels, networks of narratives, ensures that 'what is true' is relative and we need to take account of the rising importance of social culture.

Therefore, measuring and interpreting social and linguistic signals by accessing openly available online content is naturally more directly reflective of human behavior, than traditional qualitative or quantitative survey methodologies. Moreover, they also provide a coherent diagnostic base to understand, exploit and change behaviour. As an illustrative case in point, Figure 2 shows the emotional response / affect associated with COVID-19 in the UK for a year since the first lockdown in March 2020. This analysis indicates what people are feeling, about COVID-19, daily. In these unusual times with heightened uncertainty, it becomes more of an imperative to be able to communicate and connect in a relevant and credible way. It does not sample, rather looks at all 
online sources, in the UK, up to each day of the research. There is no time window. So, depending on the COVID-19 narrative, which self organizes, it could be dominated by last days news / content ... or not.

\section{TIMELESS}
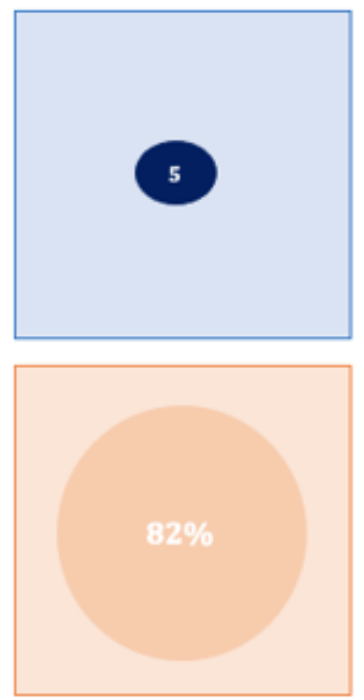

TRANSIENT
TRANSFORMATIONAL
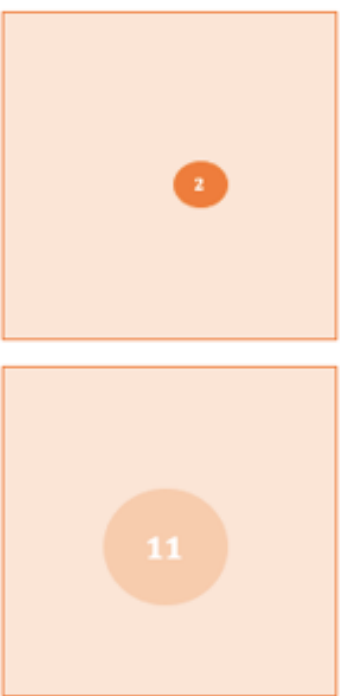

TRIBAL

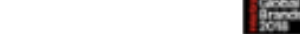

For the top 100 brands, Timeless engagement represents $\geq 90 \%$ of their narratives

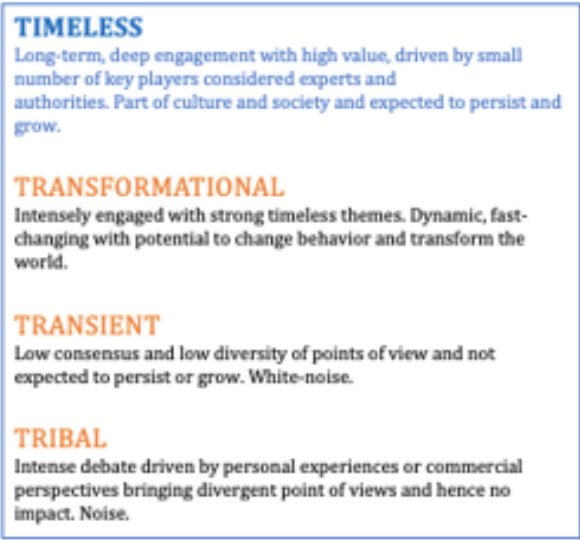
inpact. Noise.

Figure 3: Narrative engagement classification landscape @Significance Systems (used with permission).

Marketing and market research has historically been the basis on which companies that own brands have been able to keep in touch with the prospective consumers. However, the analysis capability discussed here is able on a mass scale and in an unbiased manner not affected by sampling, to understand what people want. By being able to identify what is important to people by removing much of the noise it is possible to analyze early trends that are most likely to be adopted, and how to communicate new products and services with potential consumers. Some have mooted [15] that by modernizing market research to be more precise and predictive, by moving away from legacy thinking and practice which was expensive, slow, and not exhaustive, it could reignite growth for the global, fmcg firms.

\section{Narrative Economics}

2013 Nobel Prize winner Shiller wrote the seminal text on speculative manias [16] and in arguing psychologically driven volatility was a material characteristic of asset markets warned of the tech and housing bubbles/crashes. In Narrative Economics [17], Shiller moots that the power of narratives is both broader and deeper than contemporary economics is currently willing to accept. He provides extensive empirical evidence to demonstrate that economics is driven by feelings, which are themselves driven by contagious stories. He asserts that attention-getting narratives are the most influential.

It is acknowledged that social sharing is more authentic, personal, and trustable than traditional forms of mass-age, communica- tions. Moreover, it is now possible, at scale, with data-based communications insight to:

i. objectively explore these narratives to understand the drivers and dynamics of changing behavior and consensus;

ii. probe what people value and feel are more important;

iii. establish how new solutions can be effectively dispersed to create new and better behaviours.

For this reason, The University of Tokyo's LifeStyle ${ }_{\text {by }}$ Design Research Unit initiated an investigation, in June 2019, of some lifestyle narratives that aligned with the Unit's mission to explore a holistic lifestyle design that can contribute to improved personal life satisfaction. The methodology adopted uses the Significance System approach.

The original premise was to understand what people wanted and that would enable innovation to magnify and annex on-going trends. A benchmark of attitudes and behavior was created to monitor impact, with research waves were undertaken every 6 months. Beyond this, we wished to understand how to create trust and collaboration in an evolving world so that findings could be replicable, scalable and sustainable. The study from the outset was comparative in its nature by investigating both Japan and the UK, to account for culture and a diversity of perspectives.

In the Significance Systems model, any narrative can be characterised as either transient, tribal, timeless, or transformative (Figure 3), based on the mathematical properties of the engage- 


\section{Annals of Social Sciences \& Management studies}

ment engendered by it [18]. The majority of internet exchanges are white noise ( 82 percent), having low engagement. These, referred to as transient, are poor choices for communications, since as issues, they are not expected to persist or grow. Strategically, such narratives are often easy to 'own', but they must be driven, or connected to greater relevance and/or differentiation, to have any long-term value. Tribal (11\%) narratives are characterised by intense debate, being driven by personal experiences or commercial perspectives, bringing divergent POVs. The vast majority of this debate therefore has no impact. Although it is easy to be a participant, it is far more difficult to be a player or leader in such narratives.

Those narratives that have the greatest potential utility are timeless and transformational. Timeless (5\%) narratives are expected to persist or grow. They are characterised by long-term, deep engagement. These narratives are good choices for communication activities. If one considers the narratives of the top 100 brands / corporations, then their effective communications strategies are focused. One sees Timeless engagement representing at least 90 percent of the narratives [18]. Transformational (2\%) narratives are characterised by intensely, engaged experiences with strong timeless themes. These narratives are fast-changing, yet can potentially result in a lasting transformation of the world. They were the focus of an earlier companion paper [19].

\section{Lifestyle Virtual Living Lab}

The University of Tokyo's LifeStyle ${ }_{\text {by }}$ Design Research Unit started to track, in June 2019, some 24 different narratives [3] that aligned with the Unit's mission to promote and deliver a healthiTimeless Narratives er lifestyle bringing a new balance to the physical, nutritional and social needs to enhance an individual's life satisfaction. A core tenet is to empower the individual to make their own informed choice and therefore it is key to understand what people want. That would focus innovation and communications to magnify and annex on-going trends.

An extensive and detailed analysis of engagement often uncovers that there is already a helix of engagement in play, with interlocking threads contributed by differing categories of an influencer. Many complex narratives are woven on a framework of authority and expertise. In such narratives, every category of influencer contributes a different aspect of that authority, which enriches and strengthens the narrative as a whole. For example, Significance Systems found topical drivers of engagement for the global Climate Change narrative reflect the significance of the triple helix of government, academia, and commerce. None could be easily removed or replaced without weakening the whole.

The choice of narratives took a strategic view of key communication topics. As with branded communications [15], they reflected a purpose, and rather than the majority being transient they were principally timeless, with some becoming transformational during the COVID-19 crisis [18]. The focus of this paper is on a selection of those timeless narratives, which are, as indicated earlier, useful selections for communication initiatives. The importance of narratives in understanding people's relationship with an issue cannot be overstated, nor can the important place of stories in generating new knowledge, for the individual or from a community perspective [20].

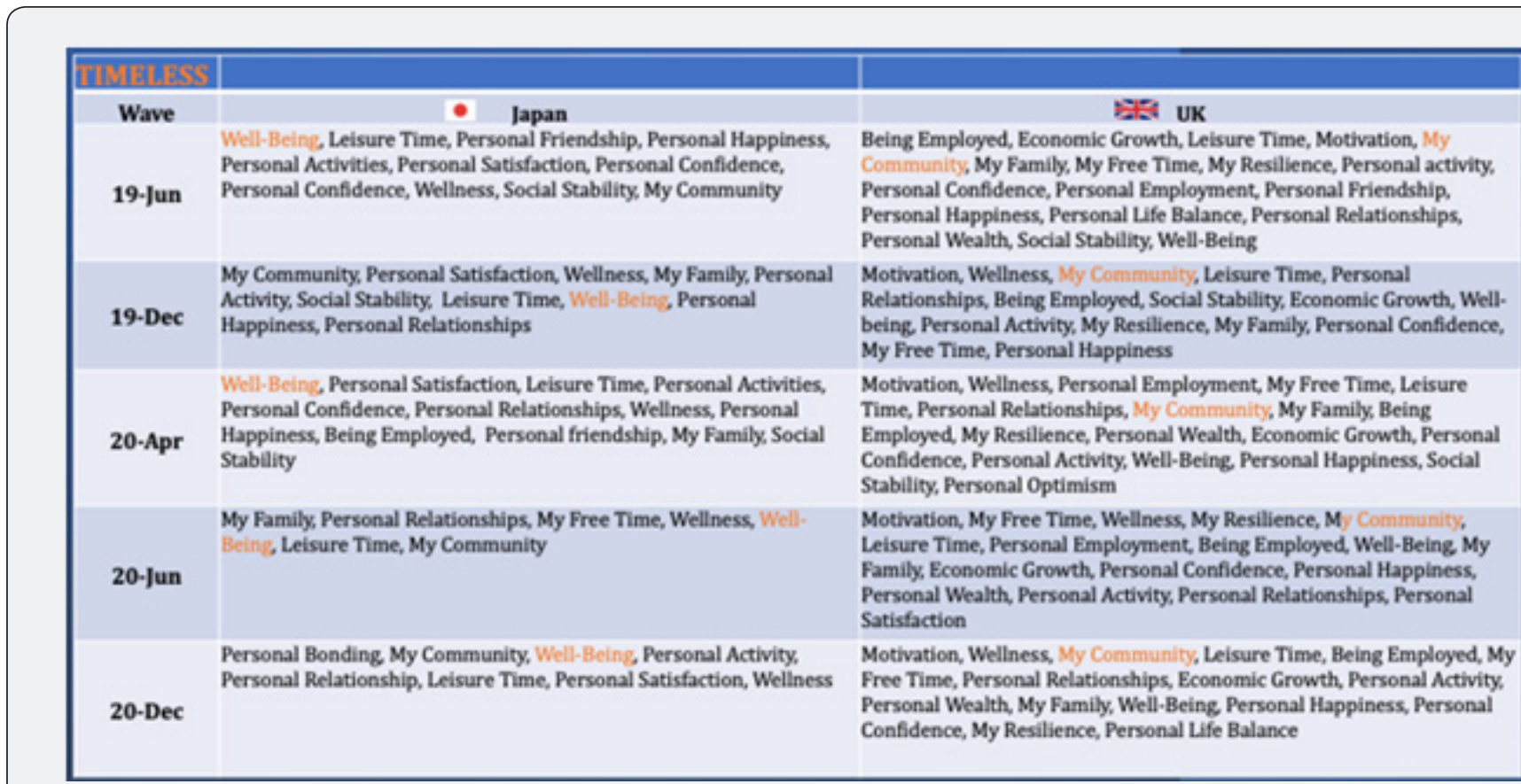

Table 1: Timeless narratives for the first 5 waves of Lifestyle research in Japan and the UK. (June 2019-December 2020). 
The timeless narratives (Figure 3) identified in the first five waves of research, from June 2019 to December 2020, are the focus of this paper (Table 1). In the first wave of June 2019, in the UK 17 and Japan 11 of the narratives, respectively, were timeless but all were currently poorly defined and therein lies an opportunity. Moreover, the timeless Japanese narratives are generally weaker than those in the UK on average.

In general, approximately 5 per cent of narratives are timeless (Figure 3). As their name suggests they are characterised by longterm, deep engagement, driven by a small number of key influencers who are often experts and authorities. Timeless narratives are authentic and matter to people. They are long-lived but are not static. It is important to be able to understand how the expression changes to remain relevant in your engagement with the narrative. This is analogous to climate and weather, and why despite climatic norms meteorological offices have, for almost 200 years, used science to provide weather forecasts.

They are good choices for themes for communications since they concern issues that are expected to persist or grow. As such they are of potential high value, but difficult to own. It is important to focus since communication power comes from the understanding of what has long-term significance, and alliance-building with the existing players. The content and the media channel contribute to communications power. The most powerful media can be social, traditional media or micro-influencers, who will influence and persuade opinion. In the same way, one can calibrate content power based on its ability to influence the audience. This is granular analyses seeking to probe what works most effectively whether is it third party voices; Infographics; video; thought pieces / white papers? What is the tone? Is it dramatising the problem, or taking a Lifestyle orientation? It is also important to track the key topics within a narrative, and their relationships, so that maintains relevancy by orientating explicitly around real problems-solutions and align with realistic expectations.

To illustrate how it is important to track timeless narratives to help maintain relevancy, this paper will look in more detail at 'well-being' in Japan, and 'my community' in the UK, from June 2019 to December 2020 (Table 1).

In June 2019, the well-being narrative, in Japan, was timeless (Figure 4a) and its affect orientation (Figure 4b) was active and positive. Significantly, these core characteristics remained the same throughout the 18-months. In June 2019, well-being' was highly engaging but poorly served by current content. Its' affect orientation was very positive being powered by enthusiasm and energy, which could enhance growth and adaptation, and thus drive new behaviour. At that time, the emotional response for well-being was skewed heavily positive and optimistic (cf. happiness; joy), so if appropriated it could empower people. The influential media, at that time, on well-being was dominated by wired. jp and to a lesser extent profile.ameba.jp.

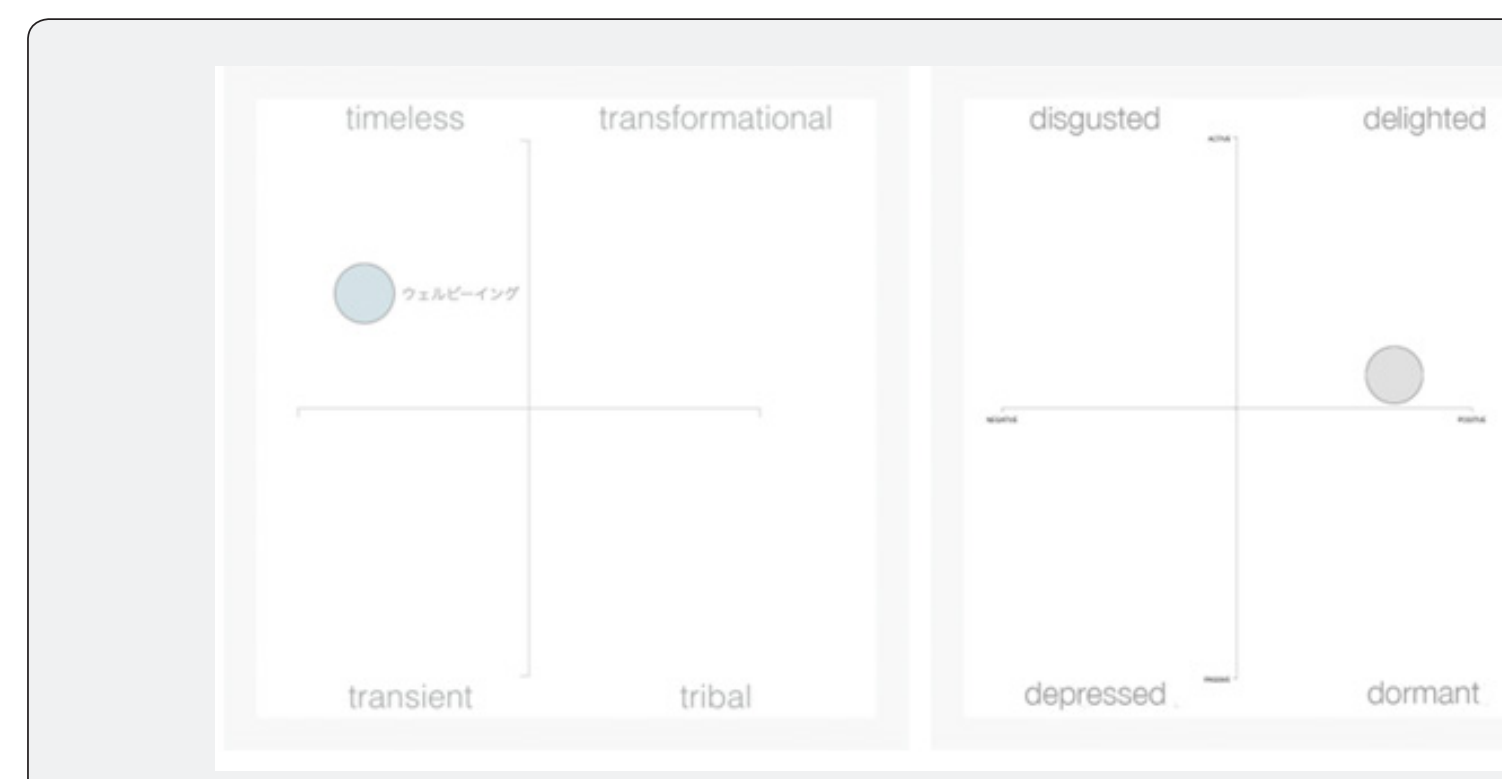

Figure 4: Well-being narrative in Japan (a) categorized and (b) Affect orientation (June 2019)

A rich measure of the emotional tone of the narrative is the affect. Being a 'felt emotion', it is a potent indicator of future behaviour. Empathy with the emotional drivers enables one to understand and respond aptly to the emotional impact of the narrative.
Well-being has a broad canvas (Figure 5). "Happiness, a sense of good and world" are compelling current topics in Japan in June 2019. Yet, they are relatively passive when compared to the topical themes in the UK at the same time. There it was more about "action, vital role, health, the well-being process, goals, and principles of sustainable development." 


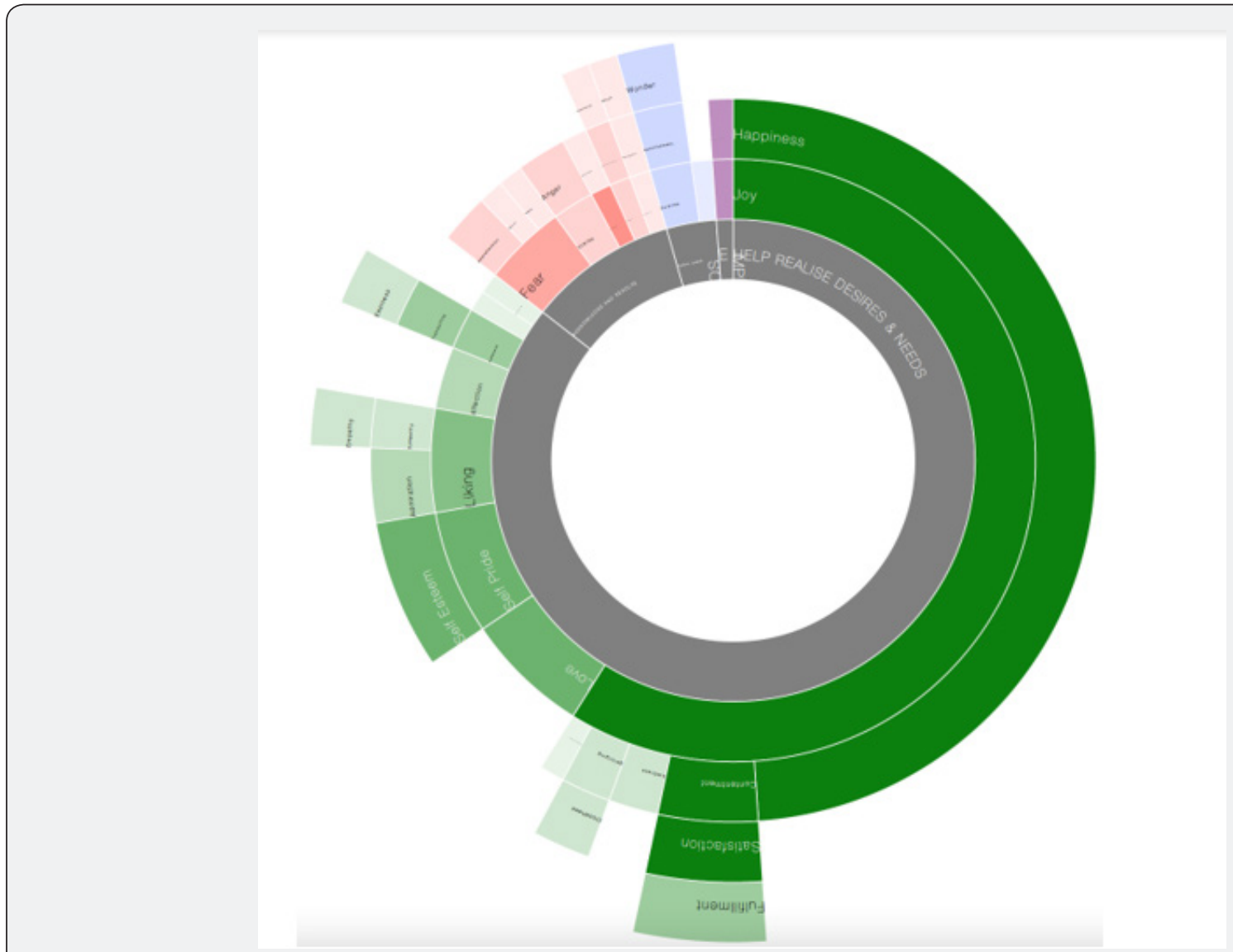

Figure 5: Well-being narrative in Japan: Affect - Emotional Response (June 2019).

In the emotional response diagram, positive emotions are highlighted in green, whereas negative emotions are red. If there is a clear tonality to the emotions expressed, such as expectation or apprehension, these are shown in purple. The intensity of the colour indicates the intensity of each emotion. The width of each arc reflects the degree to which the named emotion contributes to the overall emotional response. Broad emotions, such as fear and love, are closer to the centre of the chart. The more subtle emotions, which promote those broad emotions, are shown in the concentric rings further out from the centre. Each ring shows a further level of detail. It is usual for these more subtle emotions to have a larger cognitive component.

Health is an important element of well-being but it is no longer about illness; it is about well-being; reflecting the shift in healthcare from treatment to prevention. Therefore, it is increasingly a daily concern, thinking about diet and activity with a focus on tomorrow and an enduring healthy lifestyle. In April 2020, Japan issued the first national emergency due to COVID-19. By that time, crisis management and risk communications have come to the fore, as the pandemic creating unprecedented social, economic and political challenges as peoples around the world are having to change their lifestyles. Due to the pandemic, our be- haviour has never changed so greatly, and so immediately; characterised by limited mobility and reduced consumption. Everyone has experienced new realities when it comes to family, school, work, hygiene, and entertainment. Physical distancing has been a common theme, and this has had perhaps had the greatest impact on the family unit with large numbers teleworking, for the first time, and children being schooled at home. Compared to earlier waves the current feelings identified have become more negative emotionally (Figures $6 \& 7$ ); pessimism and distress with the present circumstances creating despair and anxiety. That said, it is evident that empathy and sympathy are becoming more liked and relevant. YouTube video was clearly the most powerful media, followed by businessinsider.jp and booklog.jp.

COVID-19 had already raised explicit consideration of employee well-being within the context of health and safety at work. Online discussions replaced live events. One such initiative taken by Nikkei Business [21] invited a founding member of Rakuten (Masatada Kobayashi) to answer questions. Kobayashi-san is their CWO: Chief Well-Being Officer. Before the national emergency was initiated the study and relevance of well-being were becoming more important amongst Japanese society as witnessed by the Tonomachi well-being symposium declaration in early March [22]. 


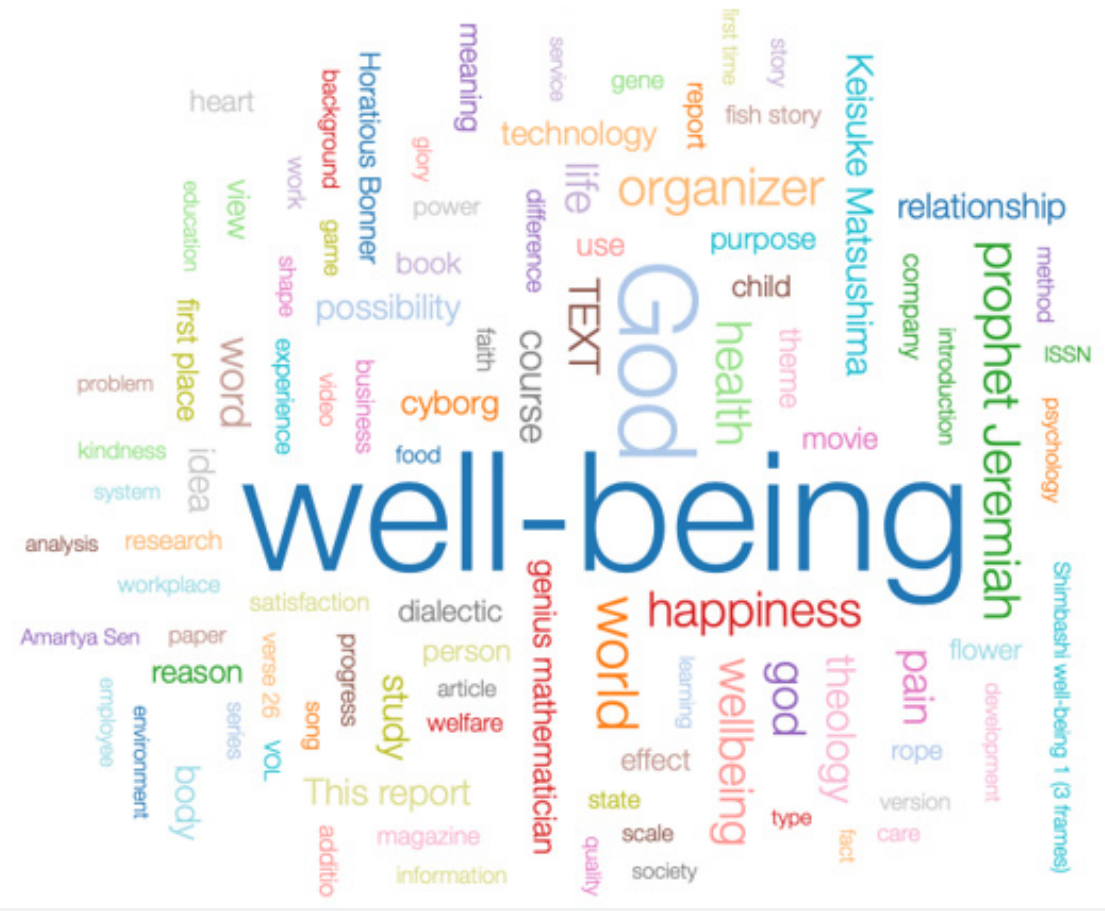

Figure 6: Well-being narrative in Japan: Key Topics (June 2019).

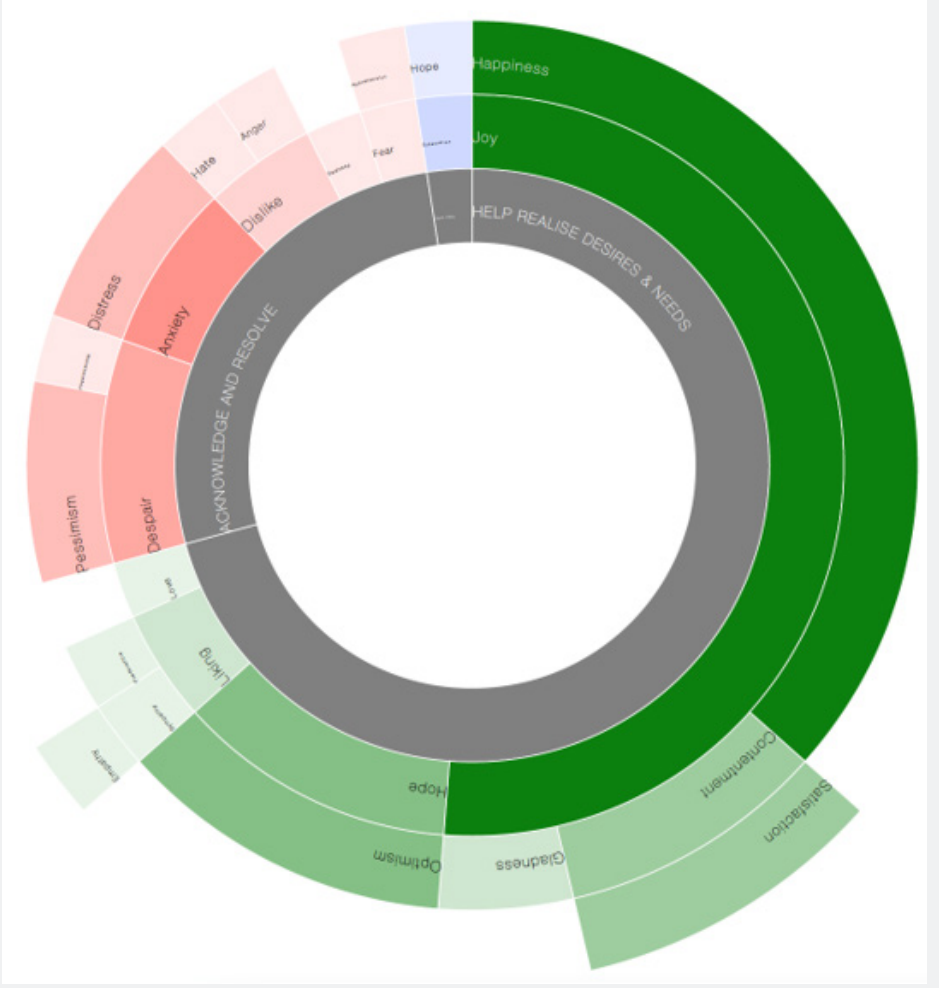

Figure 7: Well-being narrative in Japan: Affect - Emotional Response (April 2020: 1st national emergency). 
The negative emotions around well-being were relatively short-lived in Japan compared to the UK. A priori one might have expected the impact of COVID-19 to be at least as severe as other developed markets, given its proximity to China, large urban conurbations, and very skewed elderly population. Japan's population is almost twice that of the UK, but by early September 2020, the UK had reported over 350,000 cases and more than 41,500 deaths, while the corresponding figures in Japan were less than 72,000 cases and less than 1400 deaths. Comparative statistics are more extraordinary given that the national emergency in Japan did not have the same stringent mobility restrictions as the national lockdown in the UK. Traditional greetings and the culture of mask-wearing as well as social conformity [23], are likely significant contributors. This was coupled with the clear public health message to "avoid 3C's" (Closed spaces, Crowded places, and Close contact). In a broader context, The World Happiness Report 2021 [24] suggests that the reasons for the relative success of suppressing COVID-19 in Asia-Pacific was top-down, clear leadership from government coupled with bottom-up general public support of public health measures.
Thus, in December 2020 the emotional response around well-being (Figure 8), is almost wholly positive with joy and happiness dominating, although tonal cues are indicative of likely changes that might surprise. Indeed, looking at the key topics in the well-being narrative they are viewed positively (Figure 9); the most positive being the association with health. The topics that become more important during the pandemic are, by December 2020, much more focused than in June 2019. Well-being is about health in the broadest sense, it involves new perspectives on work; keeping up and tracking the latest news and research on the impact of the pandemic, while trying to enjoy and nurture a sense of happiness, with close family and friends. Purpose and connectivity are uniting us. Indeed, it is fair to say that both Japanese and British now feel more connected to family, friends and immediate neighbours. That said, it is evident that the overall impact on happiness of COVID-19 has been different, with evidence that in Japan happiness has increased, while in the UK it has declined, reflecting different levels of institutional trust [25]. That said, as we look to the future, we should support the things that unite us, and empower our local communities at scale.

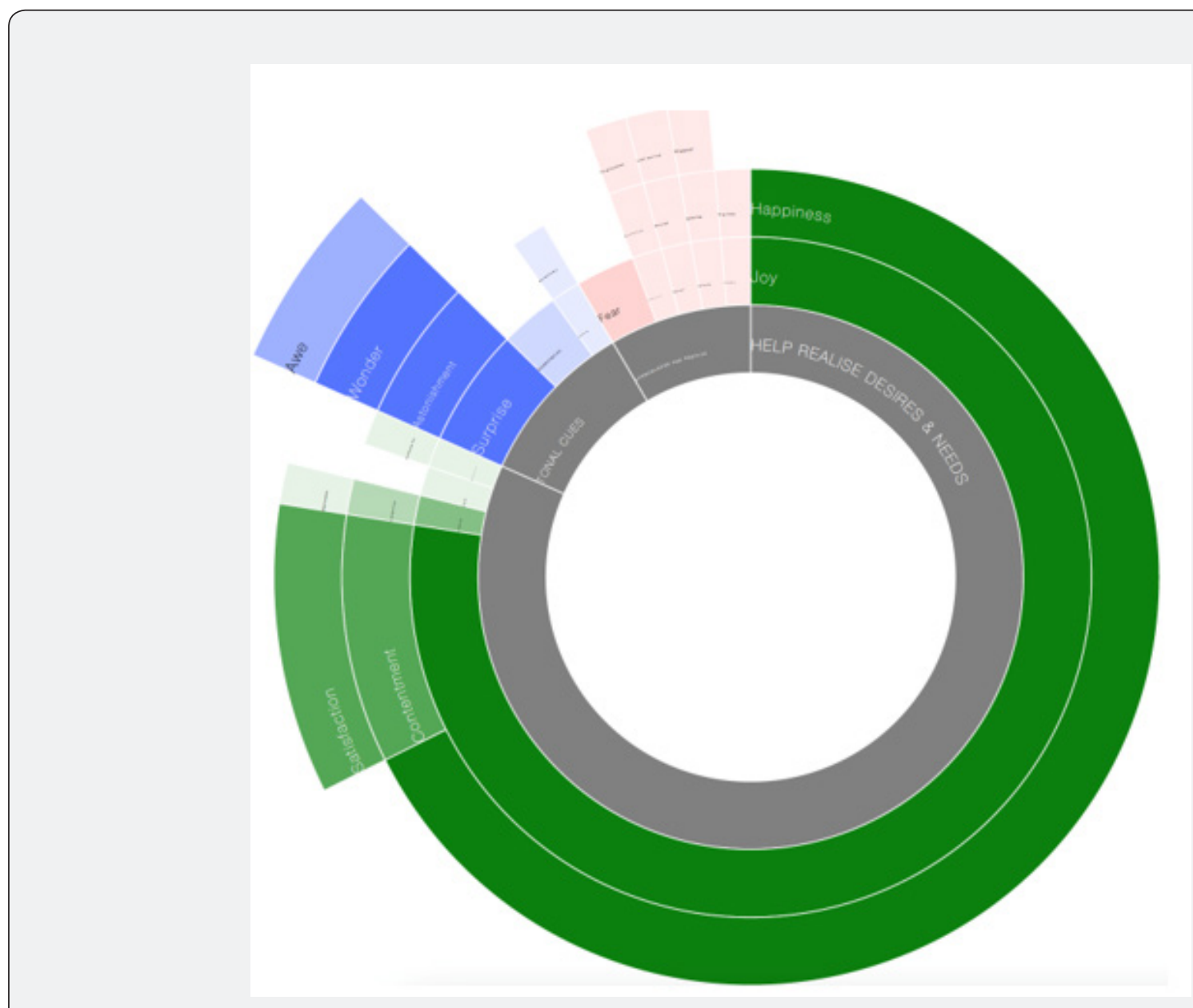

Figure 8: Well-being narrative in Japan: Affect - Emotional Response (December 2020). 


\begin{tabular}{|c|c|c|c|c|c|c|}
\hline & $\begin{array}{l}\text { h } \\
\text { e } \\
\text { a } \\
\text { I } \\
\text { t } \\
\text { h }\end{array}$ & $\begin{array}{l}w \\
0 \\
r \\
k\end{array}$ & $\begin{array}{l}\text { r } \\
\text { e } \\
\text { s } \\
\text { e } \\
\text { a } \\
\text { r } \\
\text { c } \\
\text { h }\end{array}$ & $\begin{array}{l}\text { t } \\
\text { h } \\
\text { i } \\
\text { s } \\
\text { s } \\
\text { t } \\
\text { u } \\
\text { d } \\
\text { y }\end{array}$ & $\begin{array}{l}\text { h } \\
\text { a } \\
\text { p } \\
\text { p } \\
\text { i } \\
\text { n } \\
\text { e } \\
\text { s } \\
\text { s }\end{array}$ & $\begin{array}{l}\text { w } \\
\text { e } \\
\text { I } \\
\text { I } \\
\text { - } \\
\text { b } \\
\text { e } \\
\text { i } \\
\text { n } \\
\text { g }\end{array}$ \\
\hline health & & & & & & \\
\hline work & & & & & & \\
\hline research & & & & & & \\
\hline This study & & & & & & \\
\hline happiness & & & & & & \\
\hline well-being & & & & & & \\
\hline
\end{tabular}

Figure 9: Well-being narrative in Japan: Key Topics and their relationships (December 2020).

The pandemic has strengthened the timeless (Figure 10a), role and importance of my community in providing shared resilience, in both the UK and Japan. However, before COVID-19, the UK situation was in June 2019 divided by a very public Brexit debate. At that time, the affect orientation was active and negative (Figure 10b), symbolic of the antipathy and hostility being stirred by the uncertainty around Brexit (British Exit), after the June 2016 referendum. In all future waves, the affect orientation was both active and positive.

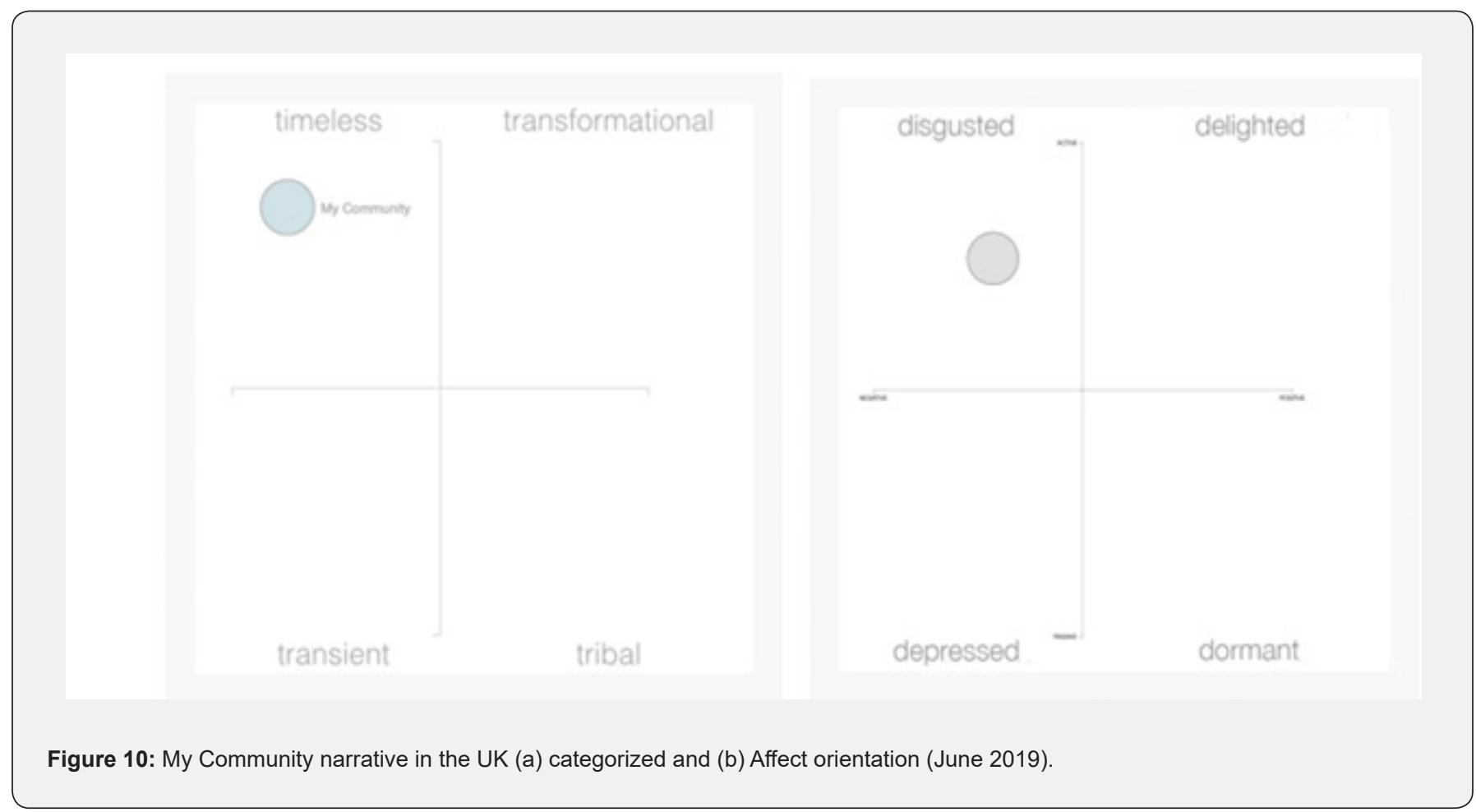


The most powerful content to capture and to drive engagement with the core themes of my community (Figure 11) came from Youtube, Facebook and GOV.UK, in June 2019. The latter via the Cabinet Office providing a detailed 'can do' guide to "organizing a voluntary event" [26], for example. In the same vein, there was material interest in CIC (community interest company); social enterprises that want to use their profits and assets for the public good. These special designated types of non-charitable, limited company were introduced, in the UK, in 2005.

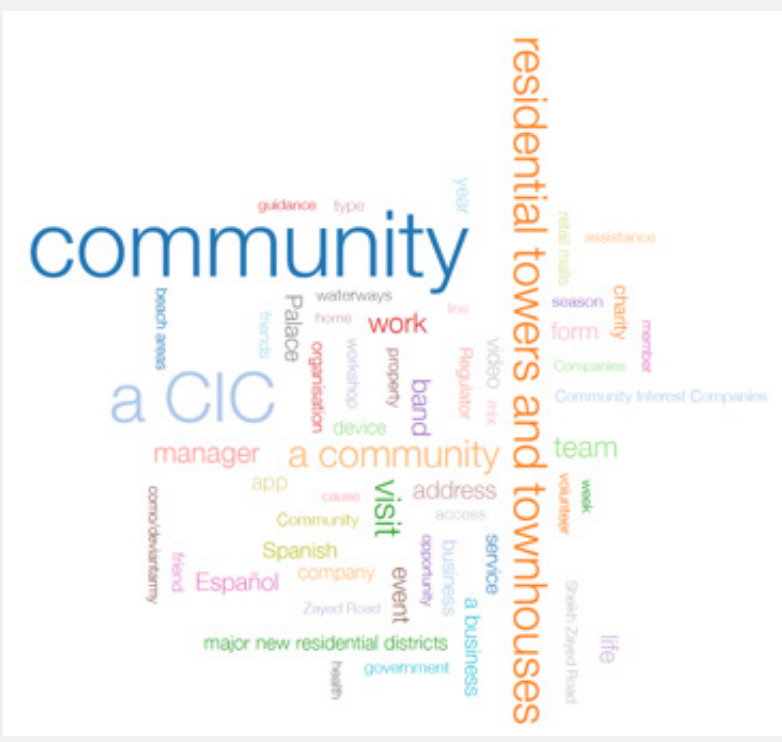

Figure 11: My Community narrative in the UK: Key Topics (June 2019).

On 12 December 2019, Boris Johnson won a majority in the UK General Election and reaffirmed his commitment to 'get Brexit done' by 31st January 2020. This was a week before the second wave of research and before COVID-19. With the uncertainty removed, there was a removal of the negativity seen in June 2019 (Figure 12a), with the beginnings of hope and with closeness creating a sense of belonging there was the beginnings of a sense of joy (Figure 12b). The latter probably reflects a seasonal effect, of
Christmas, after the relief of Brexit clarity. However, by the time of the first national lockdown in the UK in April 2020 (Figure 13) the situation had changed once again. The pandemic has distress fueling anxiety and loss creating sorrow and a sense of loss. There are negative associations between institutions and information, as communication confusion is adding to the alarm and fear (Figure 3). The anticipation, around my community, which had been evident before, in 2019, has an earnest and grave tone.

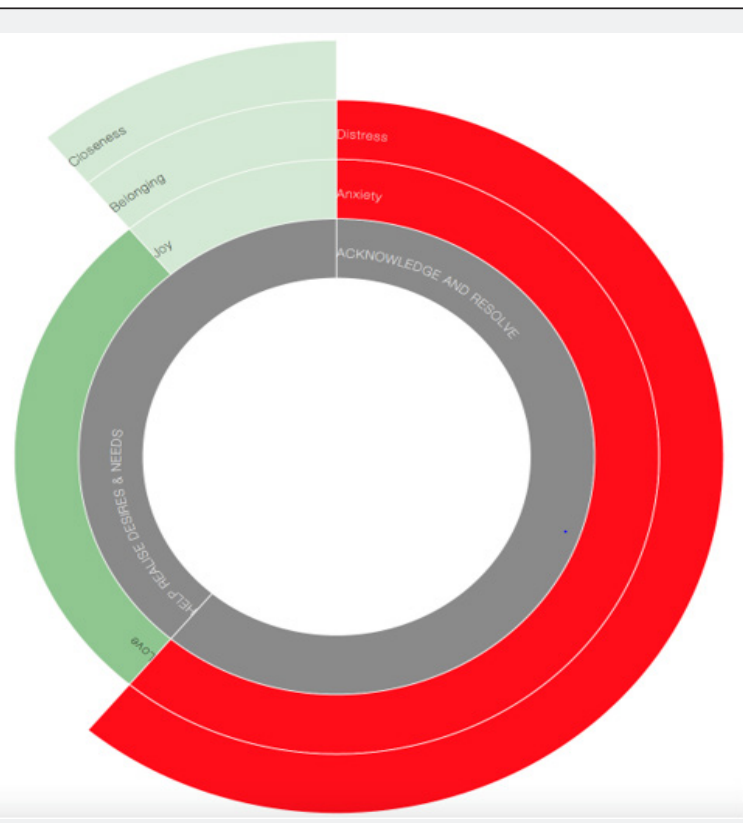

Figure 12(a): My Community narrative in the UK: Affect - Emotional Response June 2019. 
Figure 12(b): My Community narrative in the UK: Affect - Emotional Response December 2019.

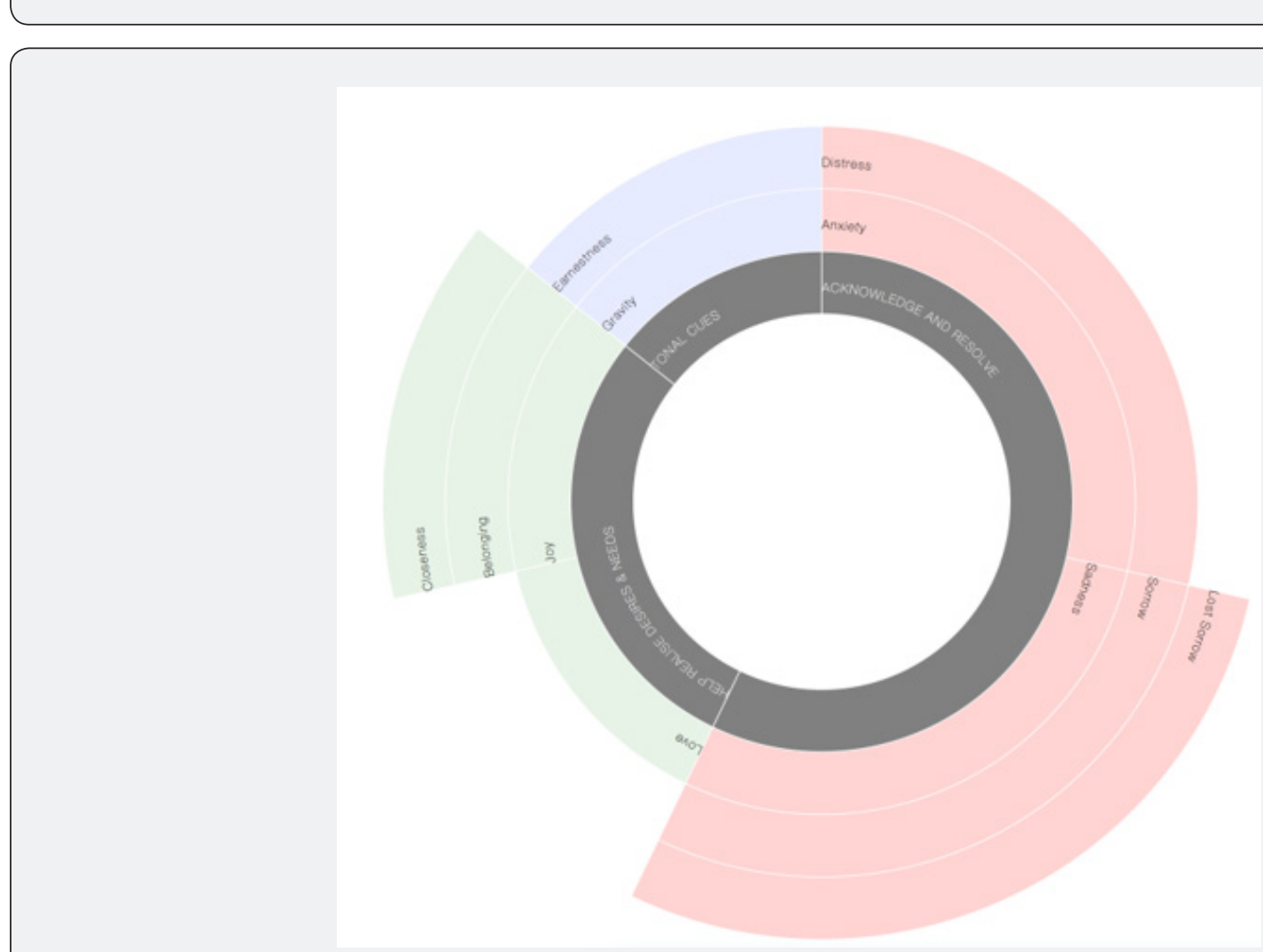

Figure 13: My Community narrative in the UK: Affect - Emotional Response (April 2020: 1st national lockdown). 
Figure 14: My Community narrative in the UK: Affect - Emotional Response (December 2020).

By December 2020, the tone has again taken a forward stance of expectation, but the affect orientation while remaining positive is neither active nor passive. There is evidence of a sense of satisfaction and contentment, as well as pride providing hope to overcome the negativity such as defeatism that drives, resignation and despair (Figure 14), as the affective orientation has remained positive, but neither active nor positive. Self-esteem and pride are being re-established and with hope, there is also a sense of calmness replacing resignation.

Direct interactions with local authority services, such as Police, Fire \& Rescue, via registered specialist and secure messaging services, outside of social media, provided powerful content for my community narrative. One such example was coined "My Community Alert" [27], in Humberside in Eastern England, which is funded by the Office of the Police and Crime Commissioner as part of their "commitment to keep you safe and well informed." Broader social digital access such as Facebook and Google Play (with apps such as MyCommunity.ai and viralbraingroup.com), as well as online neighbourhood watch sites provided platforms with strong media for community strengthening.

\section{Implications}

We are living in rapidly changing times that are charting new waters, so the imperative is to be able to track what is important to people, now. Measuring and interpreting social and linguistic signals, by accessing openly available online content, is natural- ly more directly reflective of human behavior. It can help you understand what is significant from a market's perspective and can be undertaken on a regular basis, as frequently as necessary, to monitor the mood of the society, and to empower a focused, relevant and credible response. It is more effective and efficient to engage with engagement that is already present. Schiller [17] has eloquently shown that the public's subjective perceptions that go viral can shape economic trends.

In this regard, timeless narratives offer much potential utility. Significantly, it can reassure society that their leadership is on top of an evolving situation and controlling the most appropriate narrative Something that will enhance trust. One might hypothesize that the pandemic will lead, in many countries, to a re-evaluation of the social contract. That said, we have shown that timeless narratives are not constant, and it is critical to understand how their expressions change so that you may be consistently relevant. With such an understanding policymakers or corporate leaders can focus on the important to help drive a more empathetic and relevant engagement.

With the pandemic there has been heightened inequality and mistrust. Many people have realised, after COVID-19, things can be done differently. Flexible working is likely to be mainstream [28]. No longer will the questions be about how you make up your hours, but judgement based on productivity by what you achieve is to the fore. The pandemic has created, indeed inspired a 'reset 
world' where for the first time in history business takes second place to everything else, creating a new quality to connections to family, and community. There has been resilience and a coming together, with new forms of leadership, that augers well for improving life satisfaction in the future. The reset will be permanent and there will be no going back. Going forward people will wish to reject the complex and embrace streamlining, as they focus on positive and enriching experiences, for now. Understanding what is important to us in our lives. This will involve greater participation in digital ecosystems [19] and an ever-increasing premium on the ability to be able to track ongoing stories and thus enhance communications power.

However, this paper has illustrated how insights into the narratives that can drive behaviour, at scale, may be interpreted to ensure more relevant, impactful and timely communications. It is easy to be overwhelmed by the sheer volume of content created in our networked culture. However, this paper shows how by harnessing social network analysis principles [29], from Sociometrics [30], with the automation of textual and discourse analysis through the fields of computational linguistics it is now possible to objectively and robustly provide, at scale, real-time, insights of, and action plans for, the narratives that are shaping our world. This 'what to do' offers a fundamentally different and improved way of undertaking consumer research, whether sampling for quantitative or qualitative approaches in what some have called the fast-moving and ever more complex VUCA (Volatile, Uncertain, Complex and Ambiguous) world [31]. It leverages Big Data (all open data online), to understand what is important to people, with three pillars that are transforming the research landscape [32]: (a) AI; (b) Automation; and (c) Agility for better decisions. Critically it directly aligns with how people are actually living their changing, connected and digital lives today, without fear of measurement bias.

\section{References}

1. Gans J (2020) A hidden success in the Covid-19 mess: the internet. Stat, First Opinion.

2. Gans J (2020) The Pandemic Information GapThe Brutal Economics of COVID-19. The MIT Press, United States.

3. Beaumont CD, Ricketts J (2020) A Significant Moment in History: a virtual Living Lab., LifeStyle narratives that are shaping our world; the cases of Japan and UK 2019-20. Sustainability, 12(22): 9658; Special Issue: Big Data, Knowledge Management and IoT: New Perspectives for New Challenges in Disruptive Times.

4. Kaplan AM, Haenlein M (2010) Users of the world, unite! The challenges and opportunities of Social Media. Business Horizons 53(1): 59-68.

5. Martins J, Costa C, Oliveira T, Gonçalves R, Branco F (2019) How smartphone advertising influences consumers' purchase intention. Journal of Business Research 94: 378-387.

6. Dehghani M, Niaki MK, Ramezani I, Sali R (2016) Evaluating the influence of YouTube advertising for attraction of young customers. Computers in Human Behavior 59: 165-172.

7. Edelman Trust Barometer (2021) Global Report.
8. Waldfogel J (2020) Digital Renaissance. What Data and Economics tell us about the future of Popular Culture, Princetown University Press.

9. Bercovici J (2010) Who Coined 'Social Media'? Web Pioneers Compete for Credit, Forbes.

10. Romano A (2019) 11 memes that captured the decade, The Highlight by Vox

11. Asthana A (2021) Professor Neil Ferguson on the Covid year that shattered our way of life, The Guardian, Today in Focus, Podcast.

12. McKinsey \& Company (2020) Global surveys of consumer sentiment during the coronavirus crisis, Insights, Marketing and Sales, Special Collection.

13. Alamoodi AH, Zaidan BB, Zaidan AA, Albahri OS, Mohammed KI, et al., (2021) Sentiment analysis and its applications in fighting COVID-19 and infectious diseases: A systematic review. Expert Syst Appl, Elsevier Public Health Emergency Collection 167: 114155.

14. Shelus VS, Simone C Frank, Allison J Lazard, Isabella C A Higgins, Marlyn Pulido, et al., (2020) Motivations and Barriers for the Use of Face Coverings during the COVID-19 Pandemic: Messaging Insights from Focus Groups. Int. J. Environ. Res. Public Health 17(24): 9298, Special Issue, Effects of COVID-19 on Public Health, Social Science, and Human Behaviors.

15. FT (2019) Big Brands turn to Big Data to rekindle growth. The Big Read, Retail \& Consumer Industry.

16. Shiller J (2000) Irrational Exuberance, Princeton University Press, New Zealand.

17. Shiller J (2019) Narrative Economics: How Stories Go Viral and Drive Major Economic Events, Princeton University Press, New Zealand.

18. Significance Systems: Big Data analyses.

19. Beaumont CD, Berry D, Ricketts J (2021) Objectively measuring COVID-19 transformations and identifying scalable policy determinants while explicitly accounting for the influence of culture. Ann Soc Sci Manage Stud 6(2): 555685.

20. Brunton G, James Thomas, Alison O'Mara-Eves, Farah Jamal, Sandy Oliver et al., (2017) Narratives of community engagement: a systematic review-derived conceptual framework for public health interventions. BMC Public Health 17(1): 944

21. Nikkei Business (2020)[イベント]社員の Well-being、どう目指す？How do you aim for employee well-being? Rakuten's Chief Well-being Officer, Masatada Kobayashi, speaks at the on-line event.

22. Global Gateway toward well-being society, Announcement of the Tonomachi well-being declaration; Toward the realization of a wellbeing city from Haneda-Tonomachi, Tonomachi Well-being Research Campus.

23. Gelfand MJ, Joshua Conrad Jackson, Xinyue Pan, Dana Nau, Dylan Pieper, et al., (2021) The relationship between cultural tightness-looseness and COVID-19 cases and deaths: a global analysis. Lancet Planet Health 5(3): e135-e144.

24. Sachs JD (2021) Reasons for Asia-Pacific Success in suppressing COVID-19. WHR Chapter 4.

25. The Economist (2021) It might seem crazy - The pandemic has changed the shape of global happiness.

26. GOV. UK (2019) Organizing a voluntary event, Cabinet Office, Business and Industry.

27. My Community Alert, Supporting communities in Humberside.

28. Shallenback K, Polovino S (2020) The design of work post COVID-19. Mercer Talent all Access, Short Report. 
29. Scott J, Carrington PJ (2014) The SAGE Handbook of Network Analysis.

30. Gloor PA (2017) Sociometrics and Human Relationships: Analyzing Social Networks to Manage Brands, Predict Trends, and Improve Organizational Performance, Emerald Publishing, United Kingdom.
31. Mack O, et al., (eds.,) Managing in a VUCA world, Springer International Publishing, United States.

32. Jacobson M (2020) The six trends that will change market research, according to experts, Bloomfire.
This work is licensed under Creative Commons Attribution 4.0 License

DOI: 10.19080/ASM.2021.06.555691

\section{Your next submission with Juniper Publishers will reach you the below assets}

- Quality Editorial service

- Swift Peer Review

- Reprints availability

- E-prints Service

- Manuscript Podcast for convenient understanding

- Global attainment for your research

- Manuscript accessibility in different formats

( Pdf, E-pub, Full Text, Audio)

- Unceasing customer service

Track the below URL for one-step submission https://juniperpublishers.com/online-submission.php 